\title{
Translational research in neuroanaesthesia
}

\author{
Ganne S. Umamaheswara Rao
}

\begin{abstract}
Translational research in anaesthesia provided great solutions to medicine, well beyond its scope, in the past. Exciting opportunities exist for neuroanaesthesiologists to conduct translational research not just in anaesthesia alone but in the wider realm of neurosciences. This research is expected to provide solutions to clinical neuroscience questions and to help understand some of the complex neurocognitive functions. Despite several technical developments, progress in translational sciences has been rather slow in the recent years. Re-orientation of the research programmes to a translational format with the involvement of all the stakeholders is likely to conserve the cost and provide rapid solutions to the healthcare.
\end{abstract}

Key words: Anaesthesia, neuroanaesthesia, outcome, research, translational

\section{INTRODUCTION}

"We must participate in interdisciplinary and translational research work. The director of the NIH has vowed that research of the future must involve research teams, and anesthesiologists must join these teams with the unique background we bring to all questions."- Reves JG in the $45^{\text {th }}$ Rovenstine Lecture to the American Society of Anesthesiology in 2007. ${ }^{[1]}$

Synchrony between basic science research and clinical research has been lacking for a long time. The result is a delay in transferring the laboratory and clinical research to the bedside. Resources have been wasted on ill-conceived clinical trials without a strong and unequivocal basic science background. Translational research aims to bridge the gap between basic and clinical research with the ultimate goal of advancing healthcare. The process of translational research encompasses several domains such as laboratory work,

\begin{tabular}{|l|l|}
\hline \multicolumn{2}{|c|}{ Access this article online } \\
\hline Quick Response Code: & Website: \\
\hline & www.jnaccjournal.org \\
\cline { 2 - 2 } & \\
\hline
\end{tabular}

clinical demands, health management policies and health economics. Successful translational research requires channelisation of all the involved research teams into a translational path. ${ }^{[2]}$

Successful translational research is a laborious process and may have to overcome scientific, financial, ethical, regulatory, legislative and practical hurdles. Among the stakeholders involved in the process, each may have a different expectation from the programme. For the academia, it is an opportunity to generate novel ideas and turn them into clinical applications. It is process of identification of novel scientific hypotheses through direct observation of humans and their diseases. For physicians, laboratory professionals and patients, it as a mechanism to close the gap between the bench and bedside and transfer of diagnostic and therapeutic advances to daily medical practice. For the industry, translational research provides the confidence to proceed with production. In simple terms, translational research increases the efficiency of determining the relevance of novel discoveries to human disease. It accelerates the rational transfer of new insights and knowledge into clinical practice for improving patient outcomes and public health. ${ }^{[3]}$ Thus, translational research provides a framework through which investigators or laboratories can maximise the likelihood that their research product gets adopted into medical practice.

Department of Neuroanaesthesia, National Institute of Mental Health and Neurosciences (NIMHANS), Bangalore, Karnataka, India

Address for correspondence:

Dr. Ganne S. Umamaheswara Rao, Department of Neuroanaesthesia, National Institute of Mental Health and Neurosciences, Bangalore - 560029 , Karnataka, India. E-mail: gsuma123@yahoo.com 
The two common courses of translational research are: Investigator driven and industry enabled. Investigator-driven research has a wider scope because it does not take into account the profit margin of research, but it is a slow process. The industry-enabled model accelerates the translational research through its power for funding the process. But industry would be interested primarily in products with potential for profit. ${ }^{[4]}$

\section{TRANSLATIONAL SCIENCE AND ANAESTHESIA}

Innovations are not new to anaesthesia. The evolution of neuroanaesthesia is a result of basic science research that could be translated into clinical practices that benefit the neurological patients in the operating rooms and intensive care units.

\section{Historical perspectives}

Anaesthesia, by itself is a great innovation of translational nature in the history of medicine. Through translational research only, the techniques have become refined and safer over time. Anaesthetics being drugs with a potential to impact every aspect of systemic physiology, anaesthesiologists had to get involved in research that embraces several areas of medicine (physiology, pharmacology, clinical medicine and patient care delivery, etc.). Translational research by anaesthesiologists has greatly transformed patient care in several areas outside anaesthesia. The following are examples of a few major successes and failures of translational work in neuroanaesthesia in the past:

\section{Brain and anaesthetics}

The contributions made Dr. J. D. Michenfelder and colleagues on the effects of anaesthetics on brain have profound impact on clinical practices in the neurological operating rooms and intensive care units. Extensive experimental research followed by clinical investigation provided concepts that could be incorporated into neuroanaesthetic practice. Their research provided evidence on several physiological and pharmacological aspects of anaesthetic actions. These studies provided insights into the effects of anaesthetics on cerebral blood flow, metabolism, flow-metabolism coupling, autoregulation, response to $\mathrm{CO}_{2}$ changes, intracranial pressure, and brain electrical activity, the knowledge that has been extremely relevant to plan a safe anaesthetic for a patient with cerebral pathology. ${ }^{[5-13]}$

\section{Cerebral ischaemia and protection}

Cerebral ischaemia and cerebral protection have been two major research areas in neurosciences. Models of global and focal ischaemia ${ }^{[14]}$ used in cerebral protection through anaesthetics have remained the standard models in subsequent research too. Over years, research in neuroanaesthetic techniques for cerebral protection has involved two major streams of interventions: Anaesthetic drugs and hypothermia.

Anaesthetics: That anaesthetics cause a considerable decrease in brain metabolism provided an attractive hypothesis to use them to protect against cerebral ischaemia. A 50-60\% reduction in CMRO2 at a clinically-relevant anaesthetic concentration appeared to be a great solution to salvage the ischaemic neurons. Experimental studies in smaller animals and primate models of global and focal ischaemia supported the concept. ${ }^{[15,16]}$ Several other potential mechanisms for protection have been unravelled in these studies. Encouraged by these results, large-scale clinical trials have been undertaken. Barbiturates have been used in clinical trials of cardiac arrest, ${ }^{[17]}$ stroke, ${ }^{[18]}$ traumatic brain injury ${ }^{[19]}$ and cardiopulmonary bypass. ${ }^{[20,21]}$ All these studies met with either disappointing results or false promises that could not be replicated. The end result was a colossal loss of time and resources and a failure of translation of laboratory studies into clinical practices. The introspection that followed offered several lessons on translational research. ${ }^{[22]}$ The fundamental lesson learnt was that animal studied conducted under experimental conditions cannot be directly translated into clinical practice. Also, consistency in results of basic research should be established before undertaking large clinical trials. Clearly-defined and realistic outcome targets should be set before embarking on clinical trials to reduce the costs of translational research, avoid frustration and to hasten the translational process.

The story of mild-to-moderate hypothermia in cerebral injury is no different. Profound hypothermia has long-established beneficial effect in complex cardiac surgery. Experimental studies on mild and moderate hypothermia have documented benefit in both focal and global ischaemia. However, large-scale clinical trials have failed both in traumatic brain injury ${ }^{[23]}$ and subarachnoid haemorrhage. ${ }^{[24]}$ Benefit has been limited to only studies in cardiac arrest. ${ }^{[25,26]}$ Hypothermia has found its place in guidelines for post-resuscitation care of survivors of paediatric cardiac arrest. ${ }^{[27]}$

Several molecules, tried for cerebral protection in various forms of brain injury, have yielded uniformly disappointing results, superoxide dismutase, ${ }^{[28]}$ selfote ${ }^{[29]}$ and tirilazad, ${ }^{[30]}$ just to name a few - a royal failure of translation!

Mechanical ventilation in neurological diseases Work done during the European polio epidemics in the $1950 \mathrm{~s}^{[31,32]}$ may be considered a pioneering effort at translational science that paved the way for mechanical ventilation to save lives of patients with reversible neuromuscular diseases. Credit for successful 
mechanical ventilation of patients with Guillain-Barre syndrome, myasthenia gravis, etc., in the current day neurological practice, goes to the translational work of those early years.

\section{Cardiopulmonary resuscitation}

Pioneering work carried out by Peter Safar and colleagues in the 1960s transformed the chances of survival of patients of cardiac arrest. ${ }^{[33-37]}$ Their innovative work improved the probability of successful restoration of circulation. Provided the ischemic-hypoxic time is short, the odds of good functional survival are very high. However, very little has been done to alleviate the cerebral outcomes of those who have sustained more severe hypoxic injury.

\section{CONTEMPORARY TRANSLATIONAL RESEARCH - NEEDS, OPPORTUNITIES AND CHALLENGES}

Necessity and opportunities are driving the present day anaesthesiologists to perform research in areas, which a few decades ago would have been considered well outside the scope of the anaesthesiology. A few examples are given below:

\section{Neurotoxicity of Anaesthetics}

Neurodevelopmental concerns in neonates exposed to anaesthetics have necessitated anaesthesiologists to enter the area of research on development of nervous system. ${ }^{[38,39]}$ A systematic clinical review using Bayesian technique, concluded that there is a modestly elevated risk of adverse behavioural or developmental outcomes in 60,485 children who were exposed to anaesthesia/surgery during early childhood. The evidence, however, is considerably uncertain..$^{[40]}$ Major clinical trials are underway to explore the effect. PANDA (Pediatric Anesthesia and NeuroDevelopment Assessment) is a cohort study that will enrol 500 sibling matched pairs (1000 children) who underwent hernia surgery under general anaesthesia (ASA I-II) before 36 months of age. The children will undergo a series of neuropsychological tests between 8 and 15 years of age. ${ }^{[41]}$ The results of this study could prove interesting from a clinical standpoint.

\section{Neuroprotection}

Need for neuroprotection in several acute neurological situations has opened a vast scope for work into pathophysiological mechanisms and therapy of brain injury. The mechanisms, currently under investigation by several researchers in anaesthesia, include inflammation, necrosis, apoptosis and neuronal preconditioning. ${ }^{[42-47]}$ This work, when translated into clinical tools, may help to protect the brain during intra-operative ischaemic events.

\section{Mechanisms of Anaesthesia}

The mechanisms of anaesthetic action remain an enigma even today. It is a paradox that more than a century and a half after discovery of anaesthesia, there is no concrete understanding of its mechanism. Research, in this area implies not just exploring the mechanisms of anaesthetic action, but understanding the very basis of consciousness, ${ }^{[48]}$ which neuroscientists from various disciplines have been trying to unravel. Recent approach in this area involves study of the neural net works using sophisticated gadgets like functional magnetic resonance imaging (fMRI), ${ }^{[49-51]}$ positron transmission tomography. ${ }^{[52,53]}$ This is also a fertile domain for collaborative research across the disciplines in neurosciences, ${ }^{[5,55]}$ of which anaesthesia could play a major role.

\section{Cognition and Anaesthesia}

Post-operative cognitive dysfunction remains an under-explored area. Here again, a great scope exists for research in cognitive neurosciences. This line of research may have fallouts that may answer questions in cognitive neurosciences and help understanding phenomena like ageing, dementia and Alzheimer's disease. ${ }^{[56,57]}$

\section{Traumatic Brain Injury}

Hardly any definitive therapy exists for restoration of neuronal integrity after traumatic brain injury, excepting timely removal of mass lesions and prevention of secondary insults. This calls for translational research in two areas: Limiting the early secondary injury through better care-delivery processes (transportation, resuscitation) and simpler, effective and affordable systems for monitoring cerebral physiology - blood flow, oxygenation and metabolism - with the aim of limiting secondary injury.

\section{Cerebral Function Monitoring}

The need to preserve the neuronal viability during surgery in the operating room and in the intensive care units demands research into innovative technologies that have better sensitivity and specificity and would preferably be non-invasive and inexpensive. Very little scope exists at this time to monitor the cerebral function and the available monitors are cumbersome, expensive and labour-intensive with limited sensitivity and specificity.

\section{Monitors of the Depth of Anaesthesia}

After decades of reflection on defining the state of anaesthesia, in recent years there has been an attempt at quantification of the depth of anaesthesia, but several questions are raised about these gadgets. ${ }^{[58]}$ Bringing in objectivity into prevention of intra-operative awareness requires a lot more of translational research. This research also assumes importance on the background of several 
reports linking intra-operative depth of anaesthesia with adverse post-operative outcomes. ${ }^{[59-61]}$

\section{Sleep-Related research}

Modulation of respiration during anaesthesia with its implications for peri-operative respiratory complications, is an interesting field for research. ${ }^{[62]}$ Sleep apnoea and sleep-related disordered respiration have attracted anaesthesiologists for a long time. Naturally occurring NREM sleep and anaesthesia have been found to have neurophysiological similarities. EEG-based depth-of-anaesthesia monitors are being used in this area of research. ${ }^{[63]}$

\section{Pain Management}

Preclinical and clinical research has led to significant progress in clinical pain management. Translational pain research is a definite need as many important questions do not have definitive answers. The gap between pain research and clinical pain management is wide. Objective pain-assessment tools are far too few. The relevance of the current theories of pain mechanisms to clinical pain is not well-understood. Reliable tools for both pre-clinical and clinical pain research should be developed. Co-ordinated research is required among basic scientists, clinical investigators and pain-medicine practitioners. ${ }^{[64]}$

\section{Anaesthetics and Tumour-cell Invasion/ Proliferation}

Recent studies have shown that anaesthetics have an influence on the migration and invasion of cancer cells in the lung and colonic carcinomas. ${ }^{[65,66]}$ The exact clinical relevance of these findings is not clear at this time. But when understood, this information may have a bearing on the choice of anaesthetic during surgery for cancer. The mechanisms involved may pave the way for a new line of research into anti-malignant therapy.

\section{Complementary Systems of Medicine}

Some alternative systems of medicine have claimed ability to decrease the peri-operative pain/need for pain medications. Acupuncture and acupressure deserve systematic studies for their efficacy in providing analgesia and postoperative antiemetic effect. ${ }^{[67-69]}$

\section{Pharmacogenetics}

There is growing evidence, in the recent years, that the susceptibility of an individual to anaesthetic actions and their side effects is dependent on the genetic polymorphism. Genetic factors seem to contribute to a majority of the severe adverse drug reactions. ${ }^{[70]} \mathrm{A}$ day may come in future when anaesthetic management is likely to be assisted by genetic factors with a view to reduce the risk of side effects and undesirable actions. ${ }^{[71]}$ A similar strategy is likely in the management of acute pain relief over a shorter period of time, and prevention of acute pain becoming chronic. ${ }^{[72]}$

\section{HOW TO MAKE TRANSLATIONAL RESEARCH MORE EFFECTIVE?}

Failure to translate potential basic sciences research into clinical practices is very conspicuous in recent years. Considering the heavy resource implications of medical research, a systematic approach is required to translational research.

When potential clinical applications of basic research findings are identified, they should be first tested in a collaborative multicenter basic research project, rather than jumping into a multicenter clinical trial. Using different animal models would be preferable. The research groups are required to disclose all their data. A collective analysis of the results is to be done to decide whether a collaborative multicenter clinical trial is justified. ${ }^{[73]}$

Journals often tend to accept studies with positive data more than those with negative data, and this trend has to change where the negative results have as much clinical relevance as the positive data.

Recently, based on the recommendation of the Royal College of Anaesthetists' Academic Strategy Report, Research Council of the National Institute of Academic Anaesthesia (NIAA) in the UK conducted a survey to identify priority areas for future research. ${ }^{[74]}$ In the final analysis, the areas that emerged are as follows: (a) What interventions prevent the development of chronic pain after surgery? (b) Does epidural anaesthesia improve long-term outcomes after major elective surgery? (c) Does regional anaesthesia improve long-term outcomes after surgery? (d) What is the best management strategy for fractured neck of femur? (e) Can peri-operative interventions prevent postoperative cognitive impairment? (f) What preoperative tests can be used to modify patient care and improve outcome? (g) What interventions can prevent peri-operative cardiac complications? (h) Does tight glycaemic control improve peri-operative outcome? (i) What is the best arrangement for a pre-operative assessment clinic? (j) Does an enhanced peri-operative care package improve outcomes? (k) Does a brief period of preoperative exercise training improve outcomes after major surgery? (l) Does regional anaesthesia reduce the risk of cancer recurrence? (m) Does maintaining peri-operative blood pressure at pre-operative levels improve outcome in hypertensive patients? (n). Does hypotensive resuscitation improve outcome in active haemorrhage? (o) What peri-operative management strategies improve outcome in head injury, e.g., hyperoxia?

As can be seen, some of the areas identified concern neuroanaesthesia directly and the rest too are relevant to neuroanaesthesia as much as they are to other anaesthetics. 
A similar exercise done by the neuroanaesthesiologists may provide precise ideas on the translational research priorities to improve the outcomes of neurological patients in the operating rooms and the intensive care units.

On the whole, translational research in anaesthesia provided great solutions to medicine well beyond its scope in the past. Despite all the technical developments, progress in translational sciences has been rather slow in the recent decades. Re-orientation of the research programmes to a translational format with the involvement of all the stakeholders is likely to conserve on the resources and provide rapid solutions to the healthcare.

\section{REFERENCES}

1. Reves JG. Are what we make: Transforming research in anesthesiology: The $45^{\text {th }}$ rovenstine lecture. Anesthesiology 2007; 106:826-35.

2. Keramaris NC, Kanakaris NK, Tzioupis C, Kontakis G, Giannoudis PV. Translational research: From benchside to bedside. Injury 2008;39:643-50.

3. Littman BH, Di Mario L, Plebani M, Marincola FM. What's next in translational medicine? Clin Sci (Lond) 2007;112:217-27.

4. Lacey C, Sutherland G. Advancing neurosurgery through translational research. Neurosurgery 2013;72 Suppl 1:176-81.

5. MichenfelderJD. The $27^{\text {th }}$ Rovenstine lecture: Neuroanesthesia and the achievement of professional respect. Anesthesiology 1989;70:695-701.

6. Milde LN, Milde JH, Lanier WL, Michenfelder JD. Comparison of the effects of isoflurane and thiopental on neurologic outcome and neuropathology after temporary focal cerebral ischemia in primates. Anesthesiology 1988;69:905-13.

7. Michenfelder JD, Sundt TM, Fode N, Sharbrough FW. Isoflurane when compared to enflurane and halothane dreases the frequency of cerebral ischemia during carotid endarterectomy. Anesthesiology 1987;67:336-40.

8. Messick JM Jr, Casement B, Sharbrough FW, Milde LN, Michenfelder JD, Sundt TM Jr. Correlation of regional cerebral blood flow (rCBF) with EEG changes during isoflurane anesthesia for carotid endarterectomy: Critical rCBF. Anesthesiology 1987;66:344-9.

9. MichenfelderJD. A valid demonstration of barbiturate-induced brain protection in man-at last. Anesthesiology 1986;64:140-2.

10. Newberg LA, Milde JH, Michenfelder JD. The cerebral metabolic effects of isoflurane at and above concentrations that suppress cortical electrical activity. Anesthesiology 1983;59:23-8.

11. Steen PA, Newberg L, Milde JH, Michenfelder JD. Hypothermia and barbiturates: Individual and combined effects on canine cerebral oxygen consumption. Anesthesiology 1983;58:527-32.

12. Newberg LA, Michenfelder JD. Cerebral protection by isoflurane during hypoxemia or ischemia. Anesthesiology 1983;5:29-35.

13. Gronert GA, Michenfelder JD, Steen PA, Milde JH. Canine whole body and organ system tolerance during 24 hours deep pentobarbital anesthesia. Anesthesiology 1983;58:18-25.

14. Bar-Joseph G, Safar P, Stezoski SW, Alexander H, Levine G. New monkey model of severe-volume controlled hemorrhagic shock. Resuscitation 1989;17:11-32.
15. Gisvold SE, Safar P, Hendrickx HH, Rao G, Moossy J, Alexander $\mathrm{H}$. Thiopental treatment after global brain ischemia in pigtailed monkeys. Anesthesiology 1984;60:88-96.

16. Bleyaert AL, Nemoto EM, Safar P, Stezoski SM, Mickell JJ, Moossy J, et al. Thiopental amelioration of brain damage after global ischemia in monkeys. Anesthesiology 1978;49:390-8.

17. Safar P. Amelioration of post-ischemic brain damage with barbiturates. Stroke 1980;11:565-8.

18. Selman WR, Spetzler RF, Roessmann UR, Rosenblatt JI, Crumrine RC. Barbiturate-induced coma therapy for focal cerebral ischemia. Effect after temporary and permanent MCA occlusion. J Neurosurg 1981;55:220-6.

19. Schwartz ML, Tator CH, Rowed DW, Reid SR, Meguro K, Andrews DF. A prospective, randomized comparison of pentobarbital and mannitol. Can J Neurol Sci 1984;11:434-40.

20. Nussmeier NA, Arlund C, Slogoff S. Neuropsychiatric complications after cardiopulmonary bypass: Cerebral protection by a barbiturate. Anesthesiology 1986;64:165-70.

21. Zaidan JR, Klochany A, Martin WM, Ziegler JS, Harless DM, Andrews RB. Effect of thiopental on neurologic outcome following coronary artery bypass grafting. Anesthesiology 1991;74:406-11.

22. Doppenberg EM, Bullock R. Clinical neuro-protection trials in severe traumatic brain injury: Lessons from previous studies. J Neurotrauma 1997;14:71-80.

23. Clifton GL, Drever P, Valadka A, Zygun D, Okonkwo D. Multicenter trial of early hypothermia in severe brain injury. J Neurotrauma 2009;26:393-7.

24. Todd MM, Hindman BJ, Clarke WR, Torner JC. Intraoperative Hypothermia for Surgery Trial (IHAST) Investigators. Mild intraoperative hypothermia during surgery for intracranial aneurysm. N Engl J Med 2005;352:135-45.

25. Bernard SA, Gray TW, Buist MD, Jones BM, Silvester W, Gutteridge G, et al. Smith K. Treatment of comatose survivors of out-of-hospital cardiac arrest with induced hypothermia. N Engl J Med 2002;346:557-63.

26. Hypothermia after Cardiac Arrest Study Group. Mild therapeutic hypothermia to improve the neurologic outcome after cardiac arrest. N Engl J Med 2002;346:549-56.

27. American Heart Association. 2005 American Heart Association (AHA) guidelines for cardiopulmonary resuscitation (CPR) and emergency cardiovascular care (ECC) of pediatric and neonatal patients: Pediatric basic life support. Pediatrics 2006;117:e989-1004.

28. Muizelaar JP, Marmarou A, Young HF, Choi SC, Wolf A, Schneider RL, et al. Improving the outcome of severe head injury with the oxygen radical scavenger polyethylene glycol-conjugated superoxide dismutase: A phase II trial. J Neurosurg 1993;78:375-82.

29. Morris GF, Bullock R, Marshall SB, Marmarou A, Maas A, Marshall LF. Failure of the competitive N-methyl-D-aspartate antagonist Selfotel (CGS 19755) in the treatment of severe head injury: Results of two phase III clinical trials. The Selfotel Investigators. J Neurosurg 1999;91:737-43.

30. Marshall LF, Maas AI, Marshall SB, Bricolo A, Fearnside M, Iannotti $\mathrm{F}$, et al. A multicenter trial on the efficacy of using tirilazad mesylate in cases of head injury. J Neurosurg 1998;89:519-25.

31. Sund Kristensen H, Lunding M. Two early Danish respirators designed for prolonged artificial ventilation. Acta Anaesthesiol Scand Suppl 1978;67:96-105.

32. Haglund G. Respiratory treatment in polio epidemics 1953-1961. Acta Anaesthesiol Scand Suppl 1962;12:25-9.

33. Safar P, Brown TC, Holtey WJ, Wilder RJ. Ventilation and 
circulation with closed-chest cardiac massage in man. JAMA 1961;176:574-6.

34. Safar P. Closed chest cardiac massage. Anesth Analg 1961;40:609-13.

35. Safar P, Brown TC, Holtey WJ. Failure of closed chest cardiac massage to produce pulmonary ventilation. Dis Chest 1962;41:1-8.

36. Safar P, Elam JO, Jude JR, Wilder RJ, Zoll PM. Resuscitative principles for sudden cardiopulmonary collapse. Dis Chest 1963;43:34-49.

37. Lind B, Snyder J, Safar P. Total brain ischaemia in dogs: Cerebral physiological and metabolic changes after 15 minutes of circulatory arrest. Resuscitation 1975;4:97-113.

38. Sanders RD, Hassell J, Davidson AJ, Robertson NJ, Ma D. Impact of anaesthetics and surgery on neurodevelopment: An update. Br J Anaesth 2013;110 Suppl 1:i53-72.

39. Krizschi M, Sultan S, Sandell J, Demeter K, Vutskits L, Toni N. Propofol anesthesia impairs the maturation and survival of adult-born hippocampal neurons. Anesthesiology 2013;118:602-10.

40. DiMaggio C, Sun LS, Kakavouli A, Byrne MW, Li G. A retrospective cohort study of the association of anesthesia and hernia repair surgery with behavioral and developmental disorders in young children. J Neurosurg Anesthesiol 2009;21:286-91.

41. Sun L. Early childhood general anaesthesia exposure and neurocognitive development. Br J Anaesth 2010;105(Suppl. 1):i61-8.

42. Zuo Z. A novel mechanism for sevoflurane preconditioning-induced neuroprotection. Anesthesiology 2012;117:942-4.

43. Bedirli N, Bagriacik EU, Emmez H, Yilmaz G, Unal Y, Ozkose Z. Sevoflurane and isoflurane preconditioning provides neuroprotection by inhibition of apoptosis-related mRNA expression in a rat model of focal cerebral ischemia. J Neurosurg Anesthesiol 2012;24:336-44.

44. Liang C, Cang J, Wang $\mathrm{H}$, Xue Z. Propofol attenuates cerebral ischemia/reperfusion injury partially using heme oxygenase-1. J Neurosurg Anesthesiol 2013;25:311-6.

45. Sanders RD, Manning HJ, Robertson NJ, Ma D, Edwards AD, Hagberg $\mathrm{H}$, et al. Preconditioning and postinsult therapies for perinatal hypoxic-ischemic injury at term. Anesthesiology 2010;113:233-49.

46. Homi HM, Jones WL, de Lange F, Mackensen GB, Grocott HP. Exacerbation of systemic inflammation and increased cerebral infarct volume with cardiopulmonary bypass after focal cerebral ischemia in the rat. J Thorac Cardiovasc Surg 2010;140:660-6.

47. Koerner IP, Gatting M, Noppens R, Kempski O, Brambrink AM. Induction of cerebral ischemic tolerance by erythromycin preconditioning reprograms the transcriptional response to ischemia and suppresses inflammation. Anesthesiology 2007;106:538-47.

48. Långsjö JW, Revonsuo A, Scheinin H. Harnessing Anesthesia and Brain Imaging for the Study of Human Consciousness. Curr Pharm Des 2013.

49. Jordan D, Ilg R, Riedl V, Schorer A, Grimberg S, Neufang S, et al. Simultaneous electroencephalographic and functional magnetic resonance imaging indicate impaired cortical top-down processing in association with anesthetic-induced unconsciousness. Anesthesiology 2013.

50. Chui J, Venkatraghavan L, Manninen P. Presurgical evaluation of patients with epilepsy: The role of the anesthesiologist. Anesth Analg 2013;116:881-8.

51. Demertzi A, Soddu A, Faymonville ME, Bahri MA, Gosseries O, Vanhaudenhuyse A, et al. Hypnotic modulation ofresting state fMRI default mode and extrinsic network connectivity. Prog Brain Res 2011;193:309-22.

52. Schlünzen L, Juul N, Hansen KV, Gjedde A, Cold GE. Regional cerebral glucose metabolism during sevoflurane anaesthesia in healthy subjects studied withpositron emission tomography. Acta Anaesthesiol Scand 2010;54:603-9.

53. Itoh T, Wakahara S, Nakano T, Suzuki K, Kobayashi K, Inoue O. Effects ofanesthesia upon 18F-FDG uptake in rhesus monkey brains. Ann Nucl Med 2005;19:373-7.

54. Brown EN, Purdon PL, Van Dort CJ. General anesthesia and altered states of arousal: A systems neuroscience analysis. Annu Rev Neurosci 2011;34:601-28.

55. Mashour GA. Integrating the science of consciousness and anesthesia. Anesth Analg 2006;103:975-82.

56. Fodale V, Ritchie K, Rasmussen L, Mandal PK. Anesthetics and Alzheimers disease: Background and research. Preface. J Alzheimers Dis 2010;22 Suppl 3:1-3.

57. Fodale V, Santamaria LB, Schiffilliti D, Mondal PK. Anaesthetics and postoperative cognitive dysfunction: A pathological mechanism mimicking Alzheimer's disease. Anaesthesia 2010;65:388-95.

58. Dahaba AA. Different Conditions That Could Result in the Bispectral Index Indicating an Incorrect Hypnotic State. Anesth Analg 2005;101:765-73.

59. Monk TG, Saini V, Weldon BC, Sigl JC. Anesthetic management and one-year mortality after noncardiac surgery. Anesth Analg 2005;100:4-10.

60. Leslie K, Myles PS, Forbes A, Chan MT. The effect of bispectral index monitoring on long-term survival in the B-aware trial. Anesth Analg 2010;110:816-22.

61. Kertai MD, Pal N, Palanca BJ, Lin N, Searleman SA, Zhang L, et al., B-Unaware Study Group. Association of perioperative risk factors and cumulative duration of low bispectral index with intermediate-term mortality after cardiac surgery in the B-Unaware Trial. Anesthesiology 2010;112:1116-27.

62. Lydic R. Reticular modulation of breathing during sleep and anesthesia. Curr Opin Pulm Med 1996;2:474-81.

63. Agarwal G, Modarres M, Zikov T, Bibian S. NREM sleep staging using WAV (CNS) index. J Clin Monit Comput 2011;25:137-42.

64. Mao J. Translational pain research: Achievements and challenges. J Pain 2009;10:1001-11.

65. Liang $\mathrm{H}$, Gu $M$, Yang $C$, Wang $H$, Wen $X$, Zhou $Q$. Sevoflurane inhibits invasion and migration of lung cancer cells by inactivating the $\mathrm{p} 38$ MAPK signaling pathway. J Anesth 2012;26:381-92.

66. Kawaraguchi Y, Horikawa YT, Murphy AN Murray F, Miyanohara A, Ali SA, et al. Volatile anesthetics protect cancer cells against tumor necrosis factor-related apoptosis-inducing ligand-induced apoptosis via caveolins. Anesthesiology 2011;115:499-508.

67. Xu M, Zhou SJ, Jiang CC, Wu Y, Shi WL, Gu HH, et al. The effects of $\mathrm{P} 6$ electrical acustimulation on postoperative nausea and vomiting in patients after infratentorial craniotomy. J Neurosurg Anesthesiol 2012;24:312-6.

68. El-Deeb AM, Ahmady MS. Effect of acupuncture on nausea and/or vomiting during and after cesarean section in comparison with ondansetron. J Anesth 2011;25:698-703.

69. Wetzel B, Pavlovic D, Kuse R, Gibb A, Merk H, Lehmann C, et al. The effect of auricular acupuncture on fentanyl requirement during hiparthroplasty: A randomized controlled trial. Clin J Pain 2011;27:262-7.

70. Chidambaran V, Ngamprasertwong P, Vinks AA, Sadhasivam S. Pharmacogenetics and anesthetic drugs. Curr Clin Pharmacol 2012;7:78-101.

71. Mikstacki A, Skrzypczak-Zielinska M, Tamowicz B, Zakerska-Banaszak O, Szalata M, Slomski R. The impact of genetic factors on response to anaesthetics. Adv Med Sci 2013;58:9-14. 
72. Allegri M, De Gregori M, Niebel T, Minella C, Tinelli C, Govoni S, et al. Pharmacogenetics and postoperative pain: A new approach to improve acute pain management. Minerva Anestesiol 2010;76:937-44.

73. Matsumoto M, Ishida K. Neuroanesthesia: From bench to bed. J Anesth 2012;26:585-8.

74. Howell SJ, Pandit JJ, Rowbotham DJ. National Institute of Academic Anaesthesia (NIAA National Institute of Academic
Anaesthesia research priority setting exercise. British J Anaesth 2012;108:42-52.

How to cite this article: Umamaheswara Rao GS. Translational research in neuroanaesthesia. J Neuroanaesthesiol Crit Care 2014;1:13-9.

Source of Support: Nil, Conflict of Interest: None declared.

\section{Author Help: Reference checking facility}

The manuscript system (www.journalonweb.com) allows the authors to check and verify the accuracy and style of references. The tool checks the references with PubMed as per a predefined style. Authors are encouraged to use this facility, before submitting articles to the journal.

- The style as well as bibliographic elements should be $100 \%$ accurate, to help get the references verified from the system. Even a single spelling error or addition of issue number/month of publication will lead to an error when verifying the reference.

- $\quad$ Example of a correct style Sheahan P, O'leary G, Lee G, Fitzgibbon J. Cystic cervical metastases: Incidence and diagnosis using fine needle aspiration biopsy. Otolaryngol Head Neck Surg 2002;127:294-8.

- Only the references from journals indexed in PubMed will be checked.

- $\quad$ Enter each reference in new line, without a serial number.

- Add up to a maximum of 15 references at a time.

- If the reference is correct for its bibliographic elements and punctuations, it will be shown as CORRECT and a link to the correct article in PubMed will be given.

- If any of the bibliographic elements are missing, incorrect or extra (such as issue number), it will be shown as INCORRECT and link to possible articles in PubMed will be given. 